\title{
APPLICATIONS OF METHODOLOGY OF CALCULATION OF THE NUMBER OF CONNECTIONS (MCNC) IN SOLVING TRANSPORT ATTENDANCE
}

This paper deals with the new MCNC (Methodology of Calculation of the Number of Connections) which is focused on the problem of transport attendance in the Zilina county. Starting from the calculation of passenger demands, social-economic parameters and the resulting calculation of the modal split, the allocation of vehicle schedule into an optimisation matrix is modelled. In the last step, the MCNC algorithm calculates a number of connections to achieve optimisation. This methodology can be used with other methodologies to find a better solution for transport attendance, to find a better solution for integration of the transport system. It is also possible to use the MCNC as additional methodology to calculate economic efficiency of the transport system.

\section{Introduction}

The bus passenger transport has been faced with specific problems caused by the collapse of the government-regulated transport market. Economic problems can take various forms and be measured in various ways, including changes in technologies, etc. By and large, transport problems are assessed in terms of enlarging transport costs, reducing transport quality. A general problem is the cost level of bus operation in the context of the establishment of a harmonised and liberalised transport market. This task was solved in the IMTRASY project by a team of PhD students at the University of Zilina. They participated in Mondialogo Engineering Award, the first worldwide intercultural contest seeking ideas for sustainable technical improvements in developing countries. The first task was to develop a methodology for the future provision of accessible transport services in the Zilina county which could best meet the varying needs of people.

\section{Finding a problem}

The number of bus or railway connections per one workday was analysed in every village and town in the Žilina county. The research focused on operating time, number of connections and social-economical analysis of citizens in each village or town in the Žilina county. The research reviewed the team approach, identified various ways of improving its response to the travel needs of people and recommended a future approach. The project focused also on the possibility of integration of bus and railway passenger transport.

For methodology development it was necessary to calculate a number of bus and railway connections, which provided information about the current situation. Many bus connections follow a parallel path with railway transport. From the economical point of view, it is waste of funds.

\section{Design of methodology}

The research aimed at finding the best methodology, which can work with parameters, we identified. A design of methodology took into account the research conditions and conditions of public passenger transport system. The research compared different methodologies of modelling such as aggregate and disaggregate. Disaggregate modelling has some disadvantages such as detailed and specific input data. It is also based on specific mathematical theories, which can be used only by experts.[4] Aggregate models have more advantages for application in the new methodology. For this purpose, we decided to use the first step of aggregate models. Citizens of each village or town were analysed with the help of structural parameters which are used by transportation modelling.

\section{Proposal of methodology}

Methodology of Calculation of the Number of Connections (MCNC)

The calculation is based on high level of statistical and econometric skills. It is based on methodology of specific mobility, structural parameters and the first step of aggregate modelling. [4] The MCNC consists of 3 steps.

\section{Step1 Calculation of transport demands parameters}

The research focused on the preparation of the background parameters to assess the transport demands. The calculation needs

\footnotetext{
* Marián Gogola

Department of Road and Urban Transport, Faculty of Operation and Economics of Transport and Communications, University of Žilina, e-mail:Marian.Gogola@fpedas.utc.sk
} 
the overlook of the following social-economic parameters in every town/village:

- Total population of town/village, $(P)$,

- Economically active population, $(E A)$,

- Number of schoolchildren at the age of 6-15, (SCh),

- Children (age 0-5), (Children),

- Students (highschoolers and undergraduates), (ST),

- Number of job positions, (NJP),

- Number of job positions in tertiary sector/services, (NJP3),

- Number of places in kindergartens, elementary schools, $(F P)$,

- Number of places for students, $(S P)$.

The analysis parameters NJP, NJP3, FP and SP in each town and village were used in the calculation of number of people who must commute daily to work or school.



However, the calculation mentioned above doesn't take into account other citizens, who travel sporadically by passenger transport systems. Methodology takes into account the specific mobility in the workday. Specific mobility helps to forecast and model the number of trips, citizens make per one workday.

The next step provides a number of all passengers travelling to work, schools or for other purpose out of their own village.

For this purpose, the project designs the transport demands parameters:

- $P$ - total population in town/village

- $P T$ - the parameter indicates the number of citizens who travel daily to work or schools

- Other - the parameter indicates the number of citizens not included in PT

- Owc - the parameter indicates the number of citizens who don't use individual automobile transport (IAT) to travel to work or school,

- $T P$ - parameter indicates the total number of citizens who are potential passengers for public passenger systems,

- PIAT - percentage of number of people who travel to work or schools by IAT

\section{Calculation of transport demands parameters}

$$
\begin{aligned}
& P T=\text { work }+ \text { schoolchildren }+ \text { study } \\
& \text { Other }=P-P T \\
& \text { Owc }=\text { Other }-(\text { Other } \cdot \text { PIAT })
\end{aligned}
$$

For calculating the $O w c$ parameter, the methodology used a percentage of citizens travelling by IAT to work, schools or other destination. There was different percentage in urban and village areas: in the city area (23\%) and in the village area (19.44\%). [2] The TP parameter can be calculated using the equation as follows:

$$
T P=P T+O w c
$$

The Origin-Destination matrix was generated using the $T P$ parameter. There were data providing the information about citizens who travelled from the place of origin to other destinations. The matrix provided an exact record of citizens and their destinations. It also provided information about a number of passengers who travelled in the same direction. Based on this output, the methodology could calculate the number of connections.

\section{Step 2 Assessment of bus and rail connections}

Assessment of connections was designed with the help of average parameters $P T$ and $T P$. The research made an hypothesis that not all the people, who were potential passengers $(T P)$, would travel in the same day and at the same time. Connections were distributed according to peak hours. The total number of bus connections was calculated with the help of parameters $P T, T P$ and $B C$ for each village. The project also determined a rule that the number of connections from the village equals the number of connections to the village. Therefore, it was possible to calculate the number of connections to and from the village.

Calculation of connections can be made using the equation as follows

$N C=\frac{\left[\frac{P T+T P}{2}\right]}{V C}$

$N C$ - number of connections

$V C$ - vehicle capacity

In this step, the real number of connections was compared with the proposed number of connections. The result was the optimised number of connections based on the proposed number of connections.

\section{Step 3 Assessment of running transport flow and adaptation of} connections

The optimisation considered the time taken when a passenger travelled to and from a village. The methodology also respects that the passenger flow is not uniform and has the peak hours. [3] The passenger flow grows up in the morning (between $6 \mathrm{AM}$ and 8 AM hours) and it has higher flow rate in the traffic. In the afternoon, when passengers come back, the flow takes more time with lower flow rate (between 2 PM-5 PM). [1]

\section{Practical applications of MCNC}

The MCNC helped the IMTRASY project with optimisation of bus and railway connections in the Zilina county. The project 
also suggested the methodology for integration of bus and railway transport. This result represents saving about $27 \%$ in cost per passengerkilometer. [1]

This methodology can be used with other methodologies to find a better solution for transport attendance, to find a better solution for integration of the transport system. It will also be possible to use this MCNC as additional methodology to calculate economic efficiency of the transport system.

\section{Conclusion}

The MCNC is not only a theoretical methodology. It was for first time implemented in the IMTRASY project. The project solved the optimisation of bus and railway connections in the Žilina county. The project developed the methodology, meeting the requirements the project made. The MCNC contains an analytical solution in the field of equations in space and time. This resulted in the draft of strategy which is to develop a more fully accessible transport system in the Zilina county. This methodology could help to solve the optimisation of transport attendance and design the integration of bus and railway passenger transport.

\section{References}

[1] IMTRASY, internal project study, Žilina 2004.

[2] HOLLAREK, T., ČOREJ, J: Transport attendance of autonomous geographic unit, published EDIS of University of Zilina, 2002, ISBN 80-7100-957-1.

[3] SUROVEC, P: Technology of Passenger Transport, published EDIS, University of Žilina 1998, ISBN 80-7100-494-4.

[4] HOLLAREK, T., KUŠNIEROVÁ, J.: Methods of Modelling and Prognosis of the Transport Process, published EDIS of University of Žilina, 2000, ISBN 80-7100-673-4.

[5] SUROVEC, P., ET AL.: The Economic Model of Sustainable Mobility in a Conurbation, Grant project VEGA MS SR and SAV c.1/2623/05, University of Zilina, 2005. 